\title{
Estimation of building shape by block size
}

\author{
Taima, M. ${ }^{\mathrm{a}, *}$, Asami, Y. ${ }^{\mathrm{a}}$, Hino, K. ${ }^{\mathrm{a}}$ \\ ${ }^{a}$ Affiliation Department of Urban Engineering The University of Tokyo, email taima@ua.t.u-tokyo.ac.jp, asami@csis.u-tokyo.ac.jp, \\ hino@ua.t.u-tokyo.ac.jp \\ * Corresponding author
}

Keywords: Block, estimation, floor area ratio, GIS

\begin{abstract}
:
Block restructuring has been strongly emphasized in Japan for renovating cities. However, little is known about the relation between block size and building shape. Moreover, the shape of buildings designed on a block after restructuring is unclear. Some estimation methods for urban physical status, such as building footprint location, floor area, and land use, have been developed in previous research. Taima et al. (2016) developed a model to estimate the building footprint area by using GIS. The future image of the building footprint on various blocks is visualized. Similarly, Asami and Ohtaki (2000) developed a model to estimate detached house location. Orford (2010) developed a methodology for estimating the floor area of individual properties from digital infrastructure data. Shiravi et al. (2015) assessed the utility of some models for estimating floor area using three data sources: a geographic vector building footprint layer, a LiDAR data set, and field survey data for the south side of the city of Fredericton, Canada. They discussed the reliability and accuracy of each model. In other research, Brunner et al. (2009) extended a methodology for building height estimation and tried to improve its accuracy. Schmidt et al. (2010) presented an approach to the estimation of building density on the block scale. Land use (Debnath and Amin, 2016; Jiang and Liu, 2012) and floor area (Orford, 2010) are popular topics and estimated in previous studies of the urban field, but estimation of building shape has seldom been a focus in the literature. Threedimensional estimations of buildings cannot be found. If software to estimate building shape by block shape and other conditions was developed, it would be useful to determine urban planning, such as population estimation and landuse estimation. In this study, an estimation model is developed and applied to certain areas. In this study, the relation between block size and building shape is analyzed quantitatively, and a three-dimensional building shape is estimated by a model using an urban planning GIS data set of Tokyo (Figure 1 and 2). Results show the quantitative relation between block size and building shape, and the building shape image on the blocks. Higher buildings and buildings with a basement tend to be built in larger blocks, leading to efficient use of the maximum volume permitted in the block. In addition, the region composed by larger blocks can be spacious, because the range of building setback will be long in larger blocks. Designation of a high floor area ratio may induce integration and enlargement of blocks. Blocks are less likely to be partitioned in zones when a high floor area ratio is designated.
\end{abstract}

\section{References:}

Asami Y and Ohtaki T (2000) Prediction of the shape of detached houses on residential lots. Environment and Planning B: Planning and Design 27: 283-295.

Brunner D, Lemoine G and Bruzzone, L (2009) Estimation of building heights from detected dualaspect VHR SAR imagery using an iterative simulation and matching procedure in combination with functional analysis. 2009 IEEE radar conference, pp.1-6.

Debnath R and Amin AN (2016) A geographic information system-based logical urban growth model for predicting spatial growth of an urban area. Planning B: Planning and Design 43(3): 580-597.

Jiang, B. and Liu, X (2012) Scaling of geographic space from the perspective of city and field blocks and using volunteered geographic information. International Journal of Geographical Information Science 26(2): 215-229.

Orford S (2010) Towards a data-rich infrastructure for housing-market research: Deriving floor-area estimates for individual properties from secondary data sources. Environment and Planning B: Planning and Design 37: $248-264$.

Schmidt M, Esch T, Klein D, et al. (2010) Estimation of building density using terrasar-x-data. 2010 IEEE international geoscience and remote sensing symposium (IGARSS), pp.1936-1939.

Shiravi S, Zhong M, Beykaei SA, et al. (2015) An assessment of the utility of LiDAR data in extracting base-year floorspace and a comparison with the census-based approach. Environment and Planning B: Planning and Design 42: 708-729.

Taima M, Asami Y, Hino K, et al. (2016) Influential factors and prediction of location of building coverage in a block in Tokyo commercial zones. Theory and Applications of GIS 24(2): 85-96. 

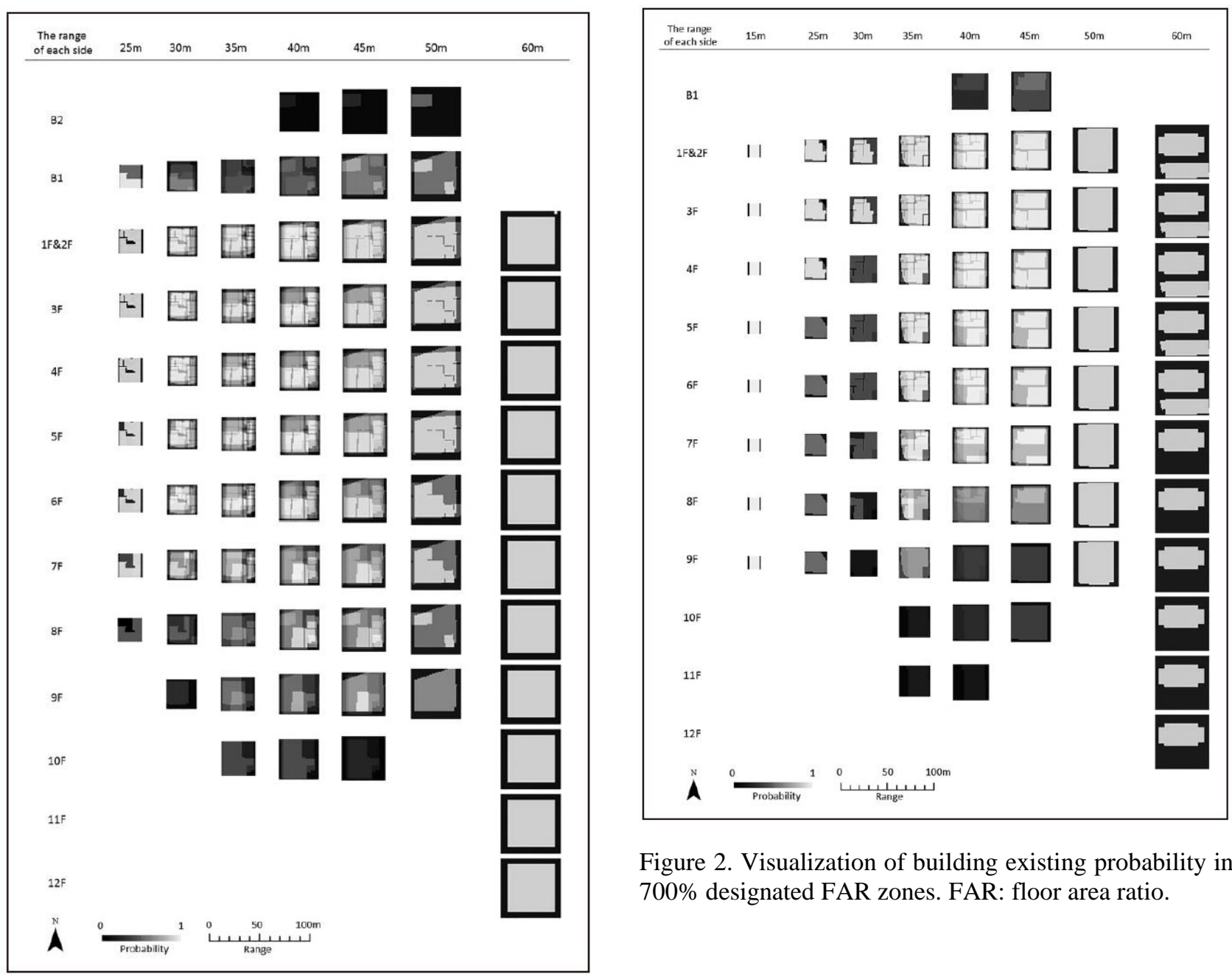

Figure 2. Visualization of building existing probability in $700 \%$ designated FAR zones. FAR: floor area ratio.

Figure 1. Visualization of building existing probability in $600 \%$ designated FAR zones. FAR: floor area ratio. 